\title{
Development of Detector Vibrating Watch Model for 100- Meter Dash Race for Visually-impaired Athletes
}

https://doi.org/10.3991/ijoe.v16i10.15617

\author{
Sri Joeda Andajani ${ }^{(凶)}$, Oce Wirawan, Pamuji \\ Universitas Negeri Surabaya, Surabaya, Indonesia \\ sriandajani@unesa.ac.id
}

\begin{abstract}
Rapidly developing technology in the 21st century brings significant change to youth education. The paradigm shift requires a change to comply to the model of technological knowledge century, including in sports. People with visual-impairment experiences movement limitations in their environment. Limited visual affects their daily activity. The 100-meter dash is one of the races performed by athletes with visually-impairment. Thus, the development of a detector vibrating watch model which can give signals or alarm when performing race in the track without an assistant is needed. The use of detector vibrating watch could help visually-impaired athletes to directly determine their position and when would they arrive to finish line. This conditioning could minimalize the crash between athletes because each athlete could finish in their respective supposed track. Thus, visually-impaired athletes could achieve their maximum time according to their ability without hindrance during the dash. However, the development of detector vibrating watch had not yet being used as assisting product in the specialized 100-meter dash for the visually-impaired. Appropriateness of this detector vibrating watch model for track dash required thinking from athletic sport, special education, and electrical engineering experts via focus group discussion. The result of expert development showed that the detector watch model was initiated from the 100-meter dash for people with visual-impairment.
\end{abstract}

Keywords - Model, detector vibrating watch, dash race, visual impairment.

\section{Introduction}

Visually-impaired is individuals experience disability of visual sense that disturb their daily activity. According to Lowenfeld, visual impairment could cause three types of limitation; (1) limitation on concept and experience diversity, (2) limitation in interacting with environment, (3) limitation in orientation and mobility [1]. Thus, visuallyimpaired often experiences movement limitation in their environment. This results in lack of concept understanding towards their surroundings.

Low-vision visually-impaired commonly prefers track as athletic sport choice, as this type of athletic have potential to raise their individual physical independency. However, there is no strong motivation from each disable individual to perform dash if they have to perform it alone, both who have and have not trained physically. Habit of having 
regular assistance causes them to keep needing assistance both for monitoring and as company [2].

Based on result of interview with physical education teachers in SMPLB/SMALB A YPAB Surabaya, most visually-impaired students at SMPLB/SMALB could perform sprint without feeling afraid of falling or crashing. However, only several visually-impaired students had talent for sprint which could be trained intensively and prepared to be an athlete. In addition, visually-impaired athletes felt difficulty if they were not assisted by sighted runner when run the track, whether it was 100-, 200-, or 400-meter. This was caused by absence of some kind of codes or alarm to signify running direction, whether it was straight or curve.

Other problems occurred is due to visual hindrance, when running in straight or curved track. Visually-impaired struggles to know the right position of straight and curved track, thus sighted runner can help them. However, there is still no model substitute for sighted runner in track, both straight and curved, at 100-meter, 200-meter with one turn, and 400-meter with four turns for visually-impaired athletes to be able to run independently. In addition, during race for visually-impaired, voiced code from assistant can possibly hard to be heard, as it competes with signal from other runner's assistants.

Lutan, Rusli [3] explained that running is a main branch of athletic. Running is also favored sport branch in athletic. Because this sport is easy to be done by everyone, without complicated rules or special location. However, in official race, such as in track, special track is made around the athletic field. All race is performed in counter-clockwise direction, starting from start line and ending in finish line. However, in several number of distance running, race is performed in road. Running branch of athletic is divided into three number; short- (sprint), middle-, and far-distance running [4-5].

Mestika [2] in her study showed that short-distance dash (sprint) could be an alternative in physical training of visually-impaired who tends to have necessity of high mobility, just as normal people who need sport to maintain body and mind balance. In people with visual impairment, running is thought to be related to their quality of life. However, the realization does not run as smoothly, as people with visual impairment experience difficulty in learning running techniques directly. Even though they can learn with their other sense, however during independent implementation, they are still feeling afraid from risks possibly occur, such as falling or crashing. This problem requires professional thinking to especially prepare running race for people with visualimpairment.

In the adaptive standard method of sprint dash for visually-impaired, they train with sighted runner as medium partner and clapping voice signal from finish line as the end of running direction. This execution has been used for parallel running for visuallyimpaired athletes partnering with sighted runner. Visually-impaired athlete run as they hang onto a rope connected to their running partner, or hand in hand with their partner. During running, intersection of visually-impaired runners can be avoided by sighted partner by putting up their bodies, so their disable partners can run in the right direction. On each step, sighted runners also ensure their disable partners of their right position by whispering it to them. Sighted partners informed the visually-impaired athletes whether they are in the right track and face the right direction. 
The other side of sprint dash for athletes with visual impairment does not differ. The use of voiced signal for start is conducted by $1^{\text {st }}$ official. In addition, other officials also perform voiced signal from sideline of track. However, body control of visually-impaired athletes are not as controlled as when running with partner, as their disability cause position change. This naturally affects their speed.

With the current development of information and communication technology, a visually-impaired athlete should be able to be independent in running sports without assistant during race. Other consideration required to help visually-impaired athletes in running sport are including train orientation and mobility skills in track and develop running sport mediums to give image about track for visually-impaired students. Instruments or mediums can be used to help visually-impaired students in running. One of them was detector vibrating watch for visually-impaired athletes in running curved track.

The development of detector medium as learning technology is designed and utilized to help learning process. Seels, Barbara \& Richey [6] stated that learning technology in developmental design is used for management and evaluation of learning process and source. Development of detector medium as part of information and communication technology, is designed and to assist visually-impaired students to be running athletes during running sport learning.

Detector is an instrument for detecting human movement using Passive Infrared Receiver (PIR) sensor and Arduiono [7]. PIR is a sensor based on infrared that could respond to change of infrared ray released by human body. Thus, PIR sensor would not release output when sensor was faced with heated objects which release 8-14 $\mu \mathrm{m}$ infrared ray or still objects. Infrared ray released by human body able to be detected by sensor had wavelength at $9-10 \mu \mathrm{m}$.

The use of Arduino has main advantage of not requiring programmer chip as it has built-in bootloader that handle upload program from computer with USB communication port, thus laptop user without port serial/RS323 can use it [8]. In addition, it also has ready-use module (Shield) that can be connected to arduino board, such as GPS shield and Ethemet.

A movement detector is often integrated to automatically performed certain task or warning of certain movement in a location [8]. In this case, running detector is a detector instrument modified to detect the movement of visually-impaired runner. The main purpose is to detect movement of runner when athlete approaching curved track and passing the detector. Detector can give signal in voice or vibrating alarm when athletes approaching curved track. With intensive exercise, athletes can easily estimate how many steps to turn according the track.

Mestika [2] in her finding explained that in doing sport activity, it had become a habit for visually-impaired athlete to be dependent to sighted guide, thus adaptive sport system is needed to be designed, which is by functioned sighted guide as assistant in every visually-impaired sport. In running athletic, visually-impaired athletes face challenge without sighted assistant. Applying technology as running assistance tools can ease athlete assistants and disable athletes themselves. When implemented in visuallyimpaired sport, sensor work in detector medium can cover as sight assistance for visually-impaired athletes. 
Based on the problem explained, a vibrating watch model was felt needed to be developed to give code or alarm assistance for visually-impaired athletes when running track without sighted guides. The use of detector put in the sideline of tracks can give signal to visually-impaired athletes on their location. This conditioning could minimalize crash between athletes due to deviation from track line when running. Thus, visually-impaired athletes could achieve their maximum time according to their talent and ability without various hindrance.

\section{$2 \quad$ Literature Review}

\subsection{Education needs and services for visually-impaired}

Legally blind is a person who has visual acuity of 20/200 or less in the better eye even with correction (e.g., eyeglasses) or has a field of vision so narrow that its widest diameter subtends an angular distance no greater than 20 degrees [9]. Children with visual impairment experience disruption of sight, resulting in hindrance of achieving optimal study achievement, except when adjustment is performed in approaching learning experience presented, properties of materials presented, and/or learning environment [10]. Loss of sight causes these three serious limitations:

- Variation and type of experience: Visually-impaired children acquire experience via factual/touch and hearing senses, while sighted children via visual sense in obtaining complete and detailed information, thus this factor affecting the variation and type of experience children obtain requires strategy and ability form them to understand this information.

- Ability to move: Sight limitation affects daily mobility greatly. This has been known long in many countries and developed in various condition with varying facilities, techniques, and styles. Visually-impaired children require independent learning in moving that accommodate their non-visual senses.

- Interacting with their environment (social and emotion): Visually-impaired children experience problems in interacting with their environment, as it is affected by behavior of parents, family, and society, which often less than accepting and cooperating. Limitation in interacting with their environment is affected by lack of sense stimulus and socialization with their surrounding society.

Based on the limitation of visual impairment explained above, it can be understood that sight limitation affects mental (experience and cognitive variation), psychic (social and emotion), and physical (mobility) factors. Cognition or thinking ability of visuallyimpaired is often disrupted, for example their mathematic and concept-understanding abilities. Visually-impaired children require variation of experience to increase their abilities and ease them in concept-understanding. This is caused by necessity of positive mental, physical, and psychic stimulus that can motivate them in learning process. 
Mental, physical, and psychic factors of visually-impaired disable children require adaptation towards condition and potential of visually-impaired. Condition and potential adaptation of visually-impaired disable can be conducted via learning approach according to context by applying varied model, suiting to materials context given. Learning appropriated to context is assumed to be able to overcome the three limitation (mental, psychic, and physical) of visually-impaired disable. Learning basis needed by visually-impaired children can be grouped as following:

- Basis of reasoning of learning needs for visually-impaired students as in sighted, that they also can teach and be taught. It means that visually-impaired students can teach themselves like sighted students. Thus, visually-impaired can be taught by actualizing potential that we have.

- Basis of learning need achievements for visually-impaired students, which including (1) basis of religion and humanity, (2) national philosophy basis, (3) positive law basis, (4) social economical basis signifying that visually-impaired requires education for them to actualize potential they have to fulfill their need, and (5) national dignity.

- Basis of a method to fulfill education needs. This including (1) equal rights with sighted children, (2) individualities, (3) based on practical skills, and (4) based on rational and reasonable attitude.

Visually-impaired facing disruption in sight but will have advantages in actualizing their potential when they are given opportunity to participate in education for hopes in their future [12]. Thus, special features in provide education for visually-impaired children should follow these principles:

- Special features: (1) use of language in learning, (2) placement of children position in the class, and (3) the availability of special program.

- Special principles: (1) scales of mental development, (2) dexterity of mobility orientation, (3) performance, and (4) repetition in giving learning.

Providing education during learning process related to its implementation directly affects finish academic tasks.

\subsection{Relationship of detector vibrating watch model with 100-meter dash running for visually-impaired}

Detector vibrating watch model is a visual example that encompass various ideas in a process or instrument system that can detect moving object, especially human. Movement detector is often integrated as component of system that automatically perfume tasks or alerts certain movement user in an area. Movement detector form an important component of security, automatic lighting control, house control, energy efficiency, and other benefiting system. Visually-impaired understanding upon the model can push their concept understanding of running activity as independency in sport tournament. 
Heinich, Molenda, Russell and Smaldino [13] explained that multimedia referred to various combination of two or more medium format integrated as information or learning program. Detector vibrating watch as multimedia equipped with controlling tools that is able to be operated by user during running in field. It is also equipped with sensor to receive signal set into sideline. The most important characteristic of this vibrating watch for running athletic is to help visually-impaired athletes to cross track. Thus, detector vibrating watch is developed by combining detector vibration audio that can receive signal from watch sensor. Detector vibrating watch is chosen based on consideration of visually-impaired athletes as medium user. It can be used by visually-impaired athletes to collect audio information as substitute of sight. Information collected can be turned to be understanding when supported by the instruments.

The process of planting concept understanding of detector vibrating watch for 100meter dash of visually-impaired athletes was started from theoretical and field review, equality of perception between experts, researcher, and user. Then, planning was done to design and collect input and recommendation from group discussion on the overview of athletic field. In relation, the production of detector vibrating watch is designed at prototype phase for 100-meter dash. The main problem of this study was;

How is the development of detector vibrating watch product for 100 -meter dash of visually-impaired athletes?

\section{Research Methods}

Method used to develop detector model watch for running for visually-impaired athletes included development phase, data collection, and data analysis.

\subsection{Research design}

In this study, research development design was used. This study developed prototype using Gall, Gall and Borg model [14] research and information collecting, planning, and develop preliminary form of product.

\subsection{Research subject}

Subject of the current study was visually-impaired athletes in F12 classification in East Java area. Determination of research subject was performed using purposive sampling based on study aim, which was discovery and development of detector vibrating watch for F12 visually-impaired running athletes.

\subsection{Procedure}

Exploration or preliminary study:Exploration or preliminary study was performed to evaluate detector vibrating watch and find various factors related to running track that could be used by visually-impaired athletes for race or tournament. Detector vi- 
brating watch was developed as an effort to facilitate visually-impaired athletes in athletic sports. The preliminary study discussed (1) analysis of detector vibrating watch that comfortable and safe to be used in 100-meter dash, (2) analysis of visually-impaired athletes needs and the availability of human resources via recruitment, and (3) prototype design of vibrating watch product to be used in 100-meter dash.

Development of detector vibrating watch prototype:The development of this model in order to develop talent potential of visually-impaired was conducted via; (1) analyzing feasibility of detector watch model design, (2) planning and developing prototype of detector vibrating watch representing the needs of visually-impaired.

Trial of detector vibrating watch: In this phase, detector watch model developed was ready to be tried. Product trial was performed by confirming developed instrument, both form quality and urgency of talent developing in visually-impaired athletes.

\subsection{Data collection}

We performed data collection by means of observation, interview, and group discussion. Intensive observation was conducted in schools for students with special needs with visually-impaired students selected in proportion based on recommendation from Education Department of East Java province. In addition, data was collected from documentation to recruit more accurate information related to race facilitated by regional and national government, up to international level. Interview was performed with confirmation of tournament implemented in province level. The aim of this method of data collection was so that data could be focused on the aim previously determined. During interview, we used cues previously prepared

- Observation technique was used to collect data related to disable tournament condition, achievement of running athletes, and issues of visually-impaired athletes during race.

- Interview was used to collect data on the identification of needs, characteristics of visually-impaired athletes, expert evaluation, and individual evaluation.

- Interview technique was used to: (1) collect information on running athletic for PEPARNAS visually-impaired athletes, and (2) collect evaluation on learning medium products of introduction to school environment using detector vibrating watch for running race from special education, running athletic, and electrical engineering experts. Observation, survey, and interview instruments were used to collect data on the needs of visually-impaired during running tournament. Instruments were arranged based on appropriate data as basic to develop detector vibrating watch for running tournament to evaluate the appropriateness of product prototype developed. Result was used as consideration to perfecting product developed.

\subsection{Data analysis}

Descriptive qualitative analysis was used to analyze review results from experts. This technique was conducted by grouping information from inputs, responses, critics, and recommendations collected during interview and focus group discussion. Result of 
analysis was used to revise vibrating watch model product for dash for visually-impaired athletes.

\section{$4 \quad$ Results and Discussion}

Prototype result of detector vibrating watch for 100-meter dash in the current study was mainly aimed as substitution of runner guide for visually-impaired athletes. Inside detector vibrating watch, these tools were arranged to detect running direction; sensor (b), digital information receiver from server that release sound wave (c); and receiver (watch model) and hand band to place receiver in runner's wrist, to receive information signaling that user have passed track or running lane.

Table 1. Instruments in True Wireless Sound

\begin{tabular}{|c|l|c|}
\hline No & \multicolumn{1}{|c|}{ Instruments } & Volume \\
\hline 1 & Arduino Mega & 4 \\
\hline 2 & Mp3 Module & 1 \\
\hline 3 & Push On switch & 324 \\
\hline 4 & Wire & 20 Meter \\
\hline 5 & Speaker & 2 \\
\hline 6 & PCB & 1 \\
\hline 7 & Powerbank & 1 \\
\hline 8 & Transformartor & 1 \\
\hline 9 & AC wire & 1 \\
\hline
\end{tabular}

Table 2. Components of Detector Vibrating Watch

\begin{tabular}{|c|l|c|}
\hline No. & \multicolumn{1}{|c|}{ Component } & Number \\
\hline 1 & Microcontroller & 4 \\
\hline 2 & Battery pack Lithium Polimer & 2 \\
\hline 3 & Smartwatch with Base Wear Os & 2 \\
\hline 4 & True Wireless Sound & 2 \\
\hline 5 & Wireles Repeater & 1 \\
\hline
\end{tabular}

Components mentioned above was used as initial model of running guide for 100meter dash for visually-impaired athletes. Experts consideration during Focus Group Discussion (FGD) in designing detector watch model was that guiding product had not previously applied for visually-impaired athletes. Sensor and detector used in watch model developed were focused to detect visually-impaired athletes put in the sideline of 100-meter track, with addition of true wireless sound (wireless earphone) to put the sensor in. Developed sensor could reach up to 10 meters onward of runner and detect other athletes in the front, which would send vibrating signal to detector in athletes' hand. Sensor design for 100-meter dash and its application are presented below.

\section{a) System Design}

1. Design of field sensor and Arduino server with Wi-FI. 


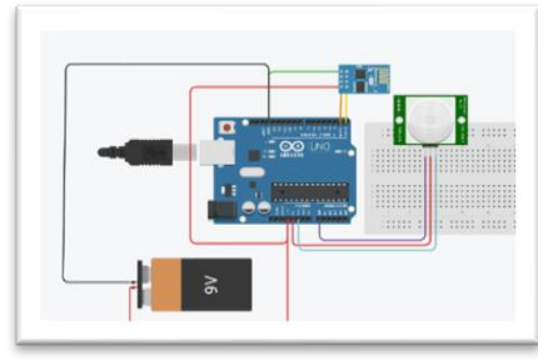

a) Field sensor design

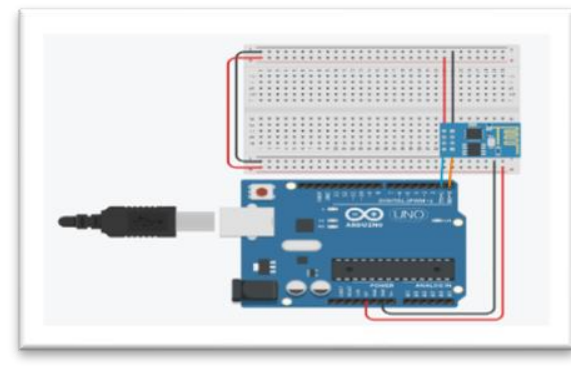

b) Server Arduino design with Wi-Fi.

Fig. 1.

2. Design of sensor component system and Wi-fi vibrating watch

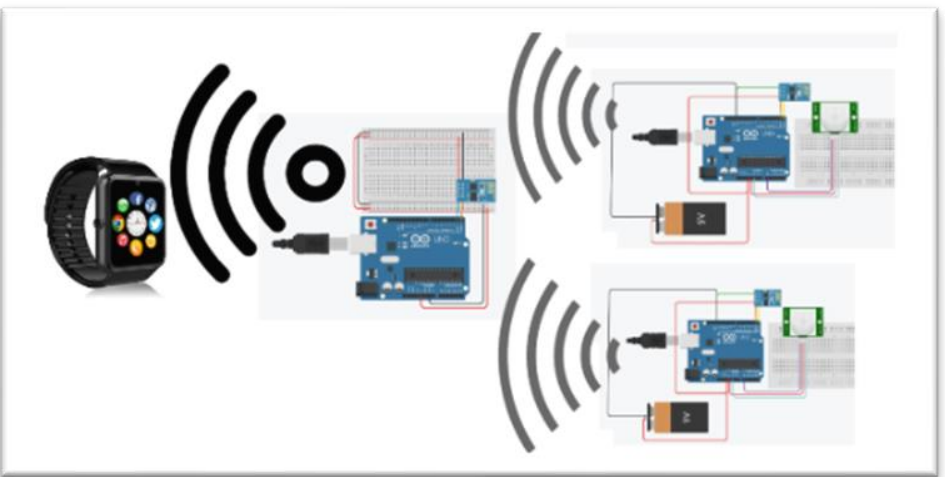

Fig. 2. Design of sensor component system and wi-fi vibrating watch 


\section{Layout design}

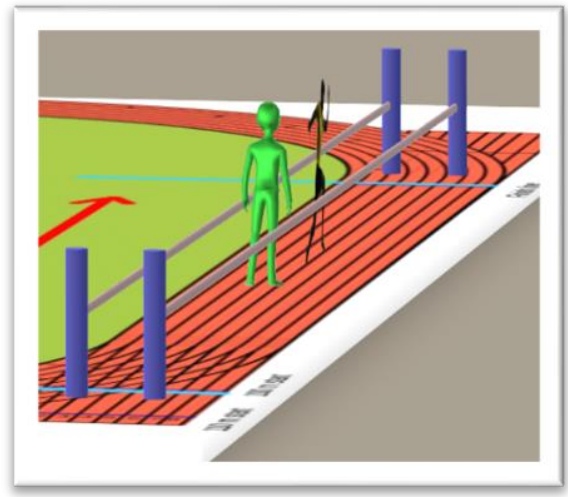

a) Animation rendering

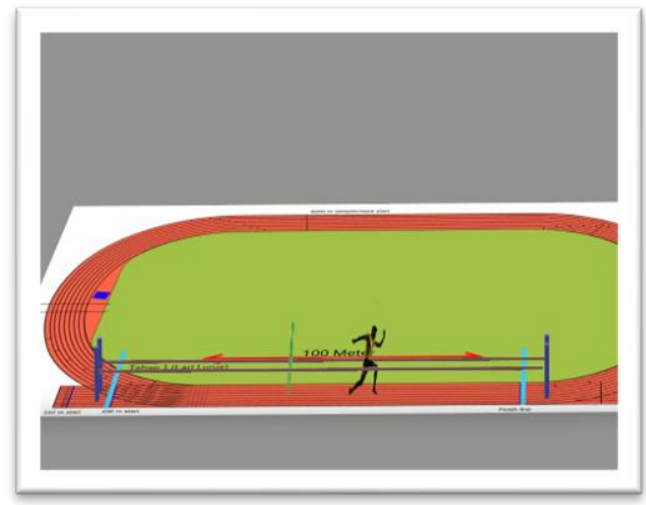

b) Animation rendering 2

Fig. 3.

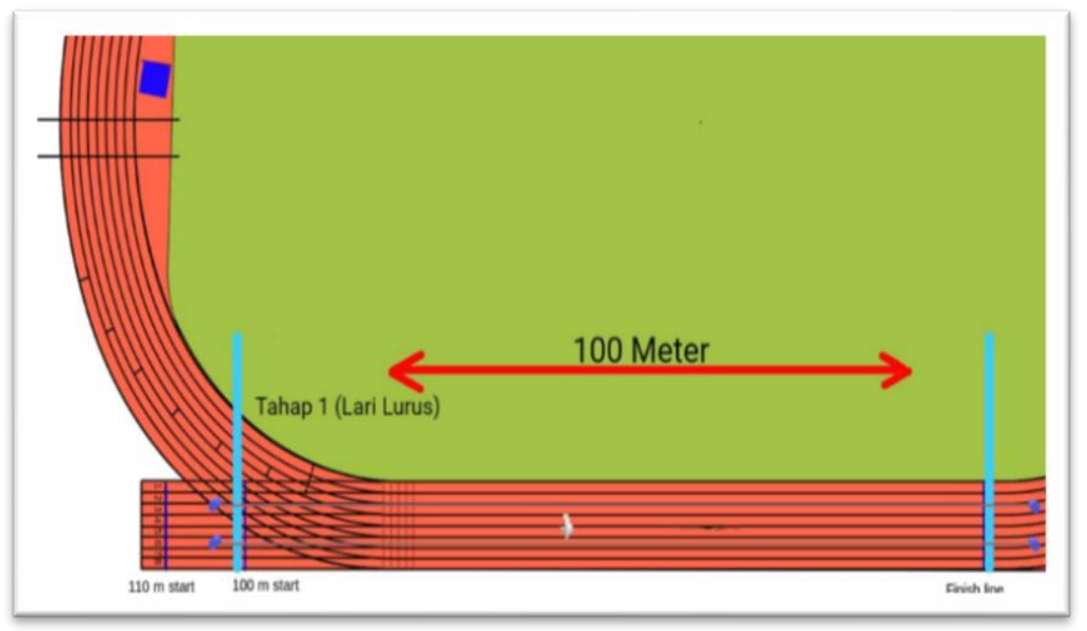

Fig. 4. Sensor Layout 
4. Detector vibrating watch instrument for 100 -meter dash
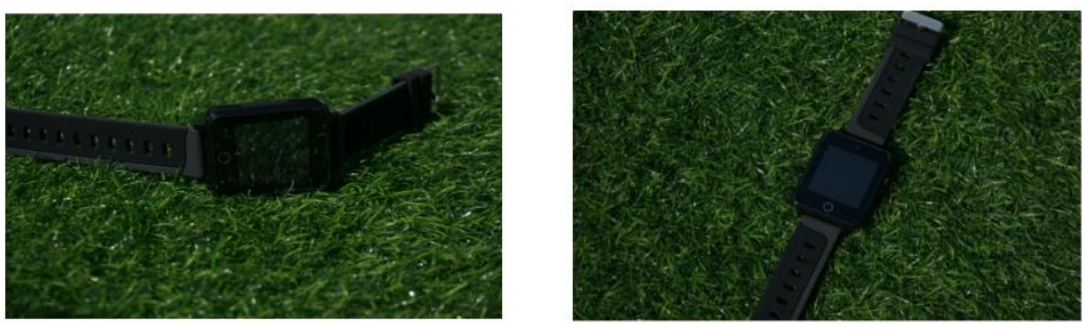

Fig. 5. Detector vibrating watch

This watch would receive information signal from server, which then would be delivered to user as vibration. Vibration conveyed to user that they have passed line or track.

5. Instrument of 100-meter dash using True Wireless Sound (wireless earphone)
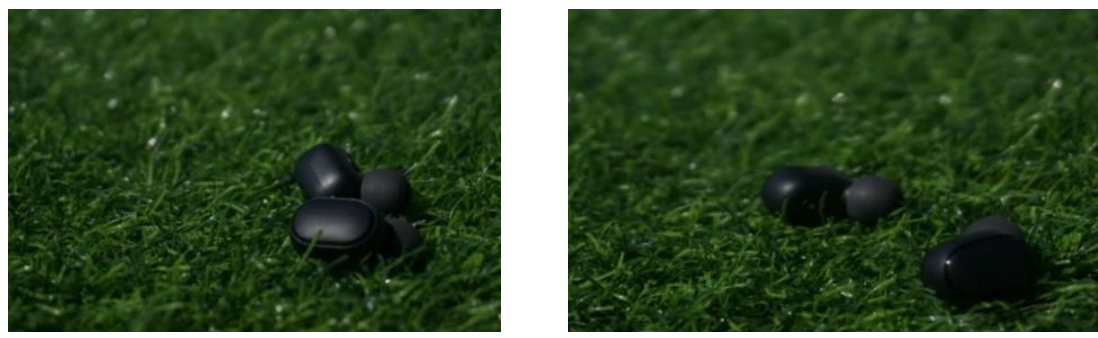

Fig. 6. True Wireless Sound

Watch model prototype was produced based on preliminary study and information collection both theoretical review and field study, initial planning and design based on environmental condition of visually-impaired athletes. As quality of orientation and mobility of visually-impaired is limited, this product can affect them in familiarizing with their surroundings. When visually-impaired experience disruption in understanding concept and surroundings, then in consequence, their orientation and mobility will also be disrupted, not excluding in Physical and Sport Education in Athletic theme. Tendencies occurred in visually-impaired is that they become passive in moving due to fear of crashing when running.

Lowenfeld emphasized that visual impairment causes three types of limitation: (1) limited concept and diversity of experience, (2) limited interaction with their surroundings, (3) limited orientation and mobility [1]. Thus, the development of detector vibrating watch for 100-meter dash for visually-impaired athletes was a solution to plant understanding of athletic sport by using detector instrument assistance to substitute runner guide. The development of this prototype referred to Gall, Gall and Borg developmental 
model [14] consisting of three steps; (1) research and information collecting, (2) planning, and (3) developing preliminary form of product. Suitability of this model was chosen to perform innovation for dash race. Developmental process of prototype watch product for dash was supported by theory from Smaldino, Sharon \& Russell, James [15]; developed product was not only in the form of learning medium, but also procedure, instruments, and learning process. Below are indicators showing that detector vibrating watch model is suitable for 100-meter dash for visually-impaired, thus in accord with IPC (International Paralympic Committee) Athletic Rules and PASI regulation.

- Research and Information Collecting was performed via fact discovery that visuallyimpaired athletes often experience crashes and deviate from their right track when running in straight line. In addition, weak concept of direction and distance is also a hindrance for visually-impaired.

- Planning is the initial step of designing prototype product of detector vibrating watch for dash. Planning is initiated with the determination of track distance in accord to disability type and classification of T11 and T12. The guideline of prototype production for sprint was according to athletic experts, athletic practitioners, electrical engineering experts, and special need experts on visually-impaired. Consideration for this prototype was that running athletic had yet to use electronical-based assistance.

- Developing preliminary form of product was through these phases; (1) designing field sensor; (b) designing Arduino server with wi-fi; (c) determining design of sensor component system and wi-fi detector vibrating watch; and (d) determining the design of sensor layout.

Based on dari 3 phases of development procedure of Gall, Gall and Borg [14] at year I of study resulted in prototype watch model for track of visually-impaired as presented in Figure 4.

Athletic track with assistance of vibrating watch model for 100-meter for visuallyimpaired athletes had never conducted previously in achievement tournament. Thus, athletic running for disable athletes with T11 and T12 classification with vibrating watch assistance can be presented in Figure 3. This track in field can be used to conduct tournament for visually-impaired athletes in F12 classification using detector vibrating watch model.

Urgent factors of development of detector vibrating watch were the guidelines of product prototype to support track for visually-impaired. This was conducted so that detector vibrating watch developed was in accord to characteristics and needs of visually-impaired. Development of detector vibrating watch for track for visually-impaired used ASSURE model based on Smaldino [15].

Design of detector vibrating watch model used for visually-impaired athletes for 100-meter dash is presented in Figure 5. This watch would receive information signal from server which then would be translated into vibration output. Information in the form of vibration in the watch would be relayed when user had passed line or track. Then true wireless sound (Figure 6) as part of this instruments would receive digital information from server, which then would be relayed to user as sound wave. Information signal accepted indicated that user had passed line or track. This was emphasized by Tang [16] that the utilization of technology for visually-impaired can ease 
them in performing various activities, when user accepted that IT-based tools can be useful and easy to use. They also tended to have positive behavior towards new technology. This was supported by previous study that proved technology implementation could help potential that students had [17], including people with disabilities [18-20].

\section{Conclusion}

Product developed in this study was detector vibrating watch equipped with true wireless sound for 100-meter sprint dash for visually-impaired athletes. Result of development showed that detector watch model could be used based on focus group discussion of experts. Product novelty was vibration from the watch functioning as code or alarm for visually-impaired when running 100-meter dash without sighted partner or assistant who gave voiced code from sideline. The use of detector put into 100-meter track could ease visually-disable athletes to directly determine their position and when they should turn. This conditioning could minimalize crashing between athletes as they could deviate from track line during dash. Implication of this result was that visuallyimpaired athletes could achieve their maximum time according to their talent and ability without hindrance at 100-meter dash. Further study can be conducted to develop this model in middle- and far-distanced track.

\section{Acknowledgement}

The authors wish to express their gratitude to the Rector Prof. Dr. Nurhasan, M.Kes, The first Vice of Rector of UNESA, Prof. Dr. Bambang Yuliyanto, M.Pd, who have supported this research in giving an opportunity to join professor acceleration and its funding; the Dean Faculty of Education UNESA Dr. Mochamad Nursalim, M.Pd and the field expert writing team.

\section{$7 \quad$ References}

[1] Lydy Reidmiller, Lauri (2003). Art For The Visually Impaired And Blind:A Case Study Of One Artist's Solution. The Ohio State University: Dissertation.

[2] Mestika, Putri Addina. (2014). Sarana Bantu Atletik Lari Tunanetra dengan Sistem Kerja Line Follower. Jurnal Online. Institut Teknologi Bandung.

[3] Lutan, Rusli. (2004). Asas-asas Pendidikan Jasmani Pendekatan Gerak Pendidikan Gerak di Sekolah Dasar. Jakarta: Direktorat Jendral Olahrga, Depdiknas.

[4] Fiqih. (2014). Cabang Atletik Lari. Diakses tanggal 21 Agustus 2017, dari https://ticihdwi.b101s:ot.co.id/ 2014/09/caban'-atletik-lari.html.

[5] Peparnas XV. (2016). Buku Panduan Teknik Peraturan Umum Cabang Olahraga Peparnas $\mathrm{XV}$.

[6] Seel, B. Barbara \& Rita C. Richey. (1994). Teknologi Pembelajaran: Definisi dan Kawasannya. (Terjemahan: Intructional Technology: The Definition and Domain of The Field). Jakarta: Unit Percetakan Universitas Negeri Jakarta. 
[7] Asyhar, Rayanda. (2012). Kreatif Mengembangkan Media Pembelajaran. Jakarta: Gaung Persada (GP) Press.

[8] Amrulloh. (2015). Implementasi Pendeteksi Gerak Manusia Dengan Sensor Passive InfraRed (PIR) Sebagai Kontrol Arah Kamera dan Sistem Pengendali Kunci Pintu dan Jendela Menggunakan Mikrokontroler. Jurnal Online. Diakses tanggal 19 Oktober 2017.

[9] Hallahan, D.P., Kauffman, J. M. \& Pullen, P.C. (2009). Exceptional Learners an Introduction to Special Education. New York: Pearson.

[10] Barraga. 1983. Pendidikan Anak Tunanetra. Yogyakarta: Pustaka Abadi.

[11] Lowenfeld, Berthold. 1979. Anak Tuna Netra di Sekolah. Teljemahan Frans Harsana Sastraningrat. Bandung: BP3 K Departemen Pendidikan dan Kebudayaan.

[12] Hosni. (2003). Pembelajaran Adaptif. Jakarta: Dirjen Dikti Depdiknas.

[13] Heinich, Molenda \& Russel. (1996). "Instructional Media”.New York: Macmillan.

[14] Gall, Gall and Borg (2003). Educational Research: An introduction Seventh Edition. Boston New York San Francisco: Pearson Education Inc.

[15] Smaldino, Sharon E \& Russel, James D. (2005). Intructional Technology and Media for Learning. Ohio, Colombus: By Pearson Education, Inc.

[16] Tang, Jenn. (2015). IT-Based Touch Panel Cognition and Development for The Visually Impaired: An Experimental Study In Taiwan. Cogn Tech Work, 17, 547-557 https://doi.org/ $\underline{10.1007 / \mathrm{s} 10111-015-0336-0}$

[17] Burns, M. (2012). Success, Failure or no Significant Difference: Charting a Course for Successful Educational Technology Integration. International Journal of Emerging Technologies in Learning, 8(1), 38-45. https://doi.org/10.3991/ijet.v8i1.2376

[18] Munir, Setiawan, W., Nugroho, E.P. \& Kusnendar, J. (2018). The Effectiveness of Multimedia in Education for Special Education (MESE) to Improve Reading Ability and Memorizing for Children with Intellectual Disability. International Journal of Emerging Technologies in Learning, 13(8), 254-263. https://doi.org/10.3991/ijet.v13i08.8291

[19] Baglama, B., Haksiz, M., \& Uzunboylu, H. (2018). Technologies Used in Education of Hearing-Impaired Individuals. International Journal of Emerging Technologies in Learning, 13(9), 54-63. https://doi.org/10.3991/ijet.v13i09.8303

[20] Mohammad, H. \& Amara, F. A. (2019). A Mobile Social and Communication Tool for Autism. International Journal of Emerging Technologies in Learning, 14(9), 159-166. https://doi.org/10.3991/ijet.v14i19.10887

\section{Authors}

Dr. Sri Joeda Andajani, Dr. Oce Wirawan, and Dr. Pamuji, work at Surabaya State University, Surabaya, Indonesia.

Article submitted 2020-05-16. Resubmitted 2020-06-17. Final acceptance 2020-06-18. Final version published as submitted by the authors. 